Supporting Information (SI) for:

\title{
Health and Climate-relevant Pollutant Concentrations from a Carbon-finance Approved Cookstove Intervention in Rural India
}

Ther W. Aung* ${ }^{1}$; Grishma Jain ${ }^{2}$; Karthik Sethuraman ${ }^{2}$; Jill Baumgartner ${ }^{3}$; Conor Reynolds ${ }^{1,4}$, Andrew P. Grieshop ${ }^{5}$, Julian D. Marshall ${ }^{3,4}$, Michael Brauer ${ }^{6}$

${ }^{1}$ Institute for Resources, Environment and Sustainability, The University of British Columbia, 2202 Main Mall, Vancouver, British Columbia, Canada V6T 1Z4. Tel: 240-205-7733. Email: theraung@alumni.ubc.ca

${ }^{2}$ Resource Optimization Initiative, No.66, 1st Floor, 1st Cross, Domlur Layout, Bangalore 560 071, India

${ }^{3}$ Institute on Environment, University of Minnesota, 1954 Buford Ave, St. Paul, MN 55108 ${ }^{\mathrm{a}}$

${ }^{4}$ Department of Civil, Environmental, and Geo- Engineering, University of Minnesota, 500 Pillsbury Drive SE, University of Minnesota, Minneapolis, MN 55455, USA ${ }^{\mathrm{b}}$

${ }^{5}$ Department of Civil, Construction and Environmental Engineering, North Carolina State University, 431B Mann Hall, Raleigh, NC 27696-7908, USA

${ }^{6}$ School of Population and Public Health, The University of British Columbia, 2206 East Mall Vancouver, British Columbia V6T 1Z3, Canada

The Supporting Information contains 29 pages (including title page), 17 figures, and 11 tables.

*Corresponding author e-mail: theraung@alumni.ubc.ca

\footnotetext{
${ }^{a}$ Baumgartner, Institute for Health and Social Policy and Department of Epidemiology, Biostatistics, and Occupational Health, McGill University, 1030 Pine Avenue West, Office \#B7, Montreal, QC H3A 1A3, Canada

${ }^{\mathrm{b}}$ Marshall, University of Washington, 201 More Hall, Box 352700, Seattle, WA 98195-2700, USA
} 


\section{MATERIALS AND METHODS SECTION}

Figure S1: Typical Two Traditional Stoves used in Study Area

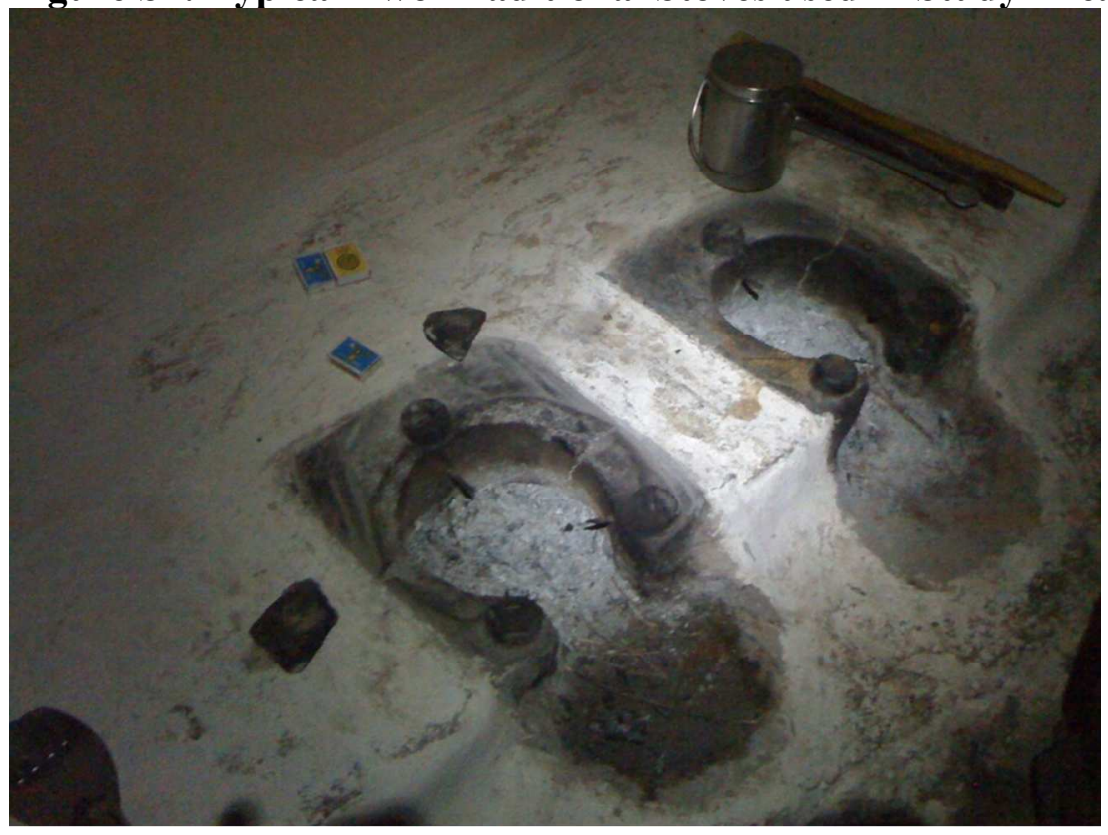

Figure S2: Intervention Stove approved for CDM Stove Intervention Program (white lines on the stoves are draw by user as part of the local cultural and religious practice)

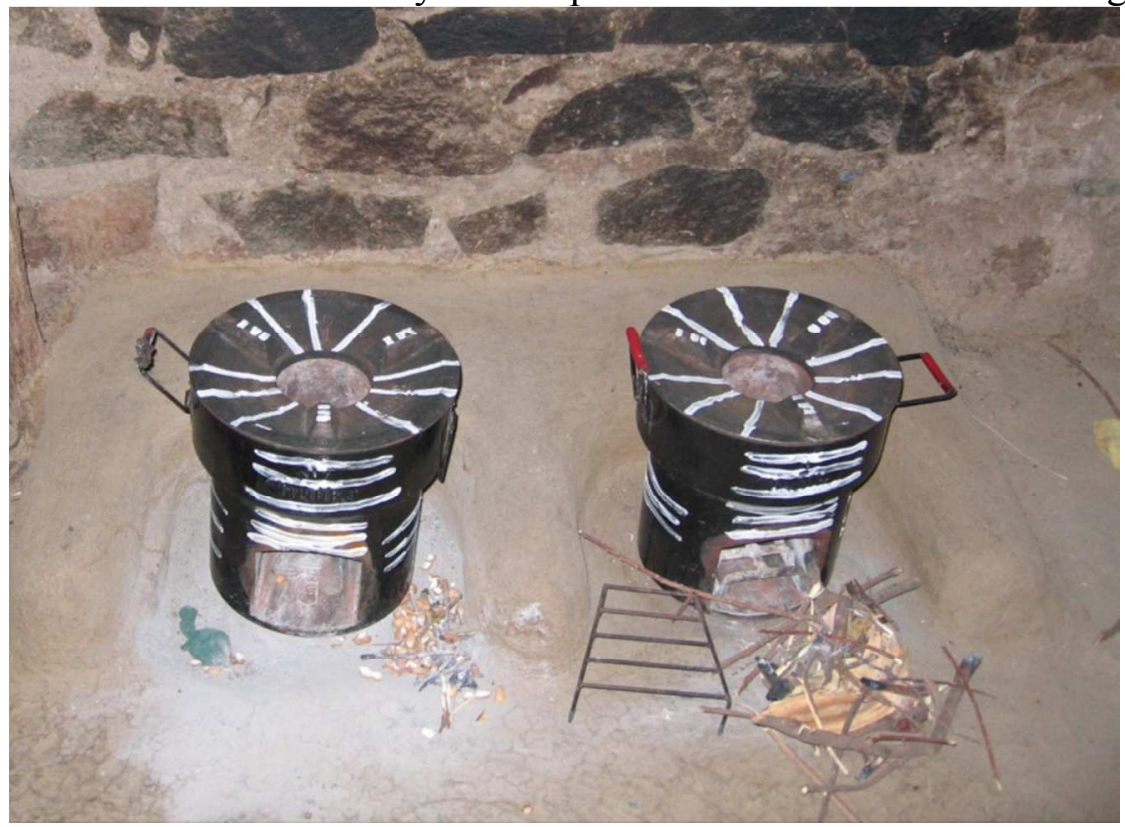




\section{Figure S3: CDM-approved Intervention Stove in Outdoor Cooking Area}

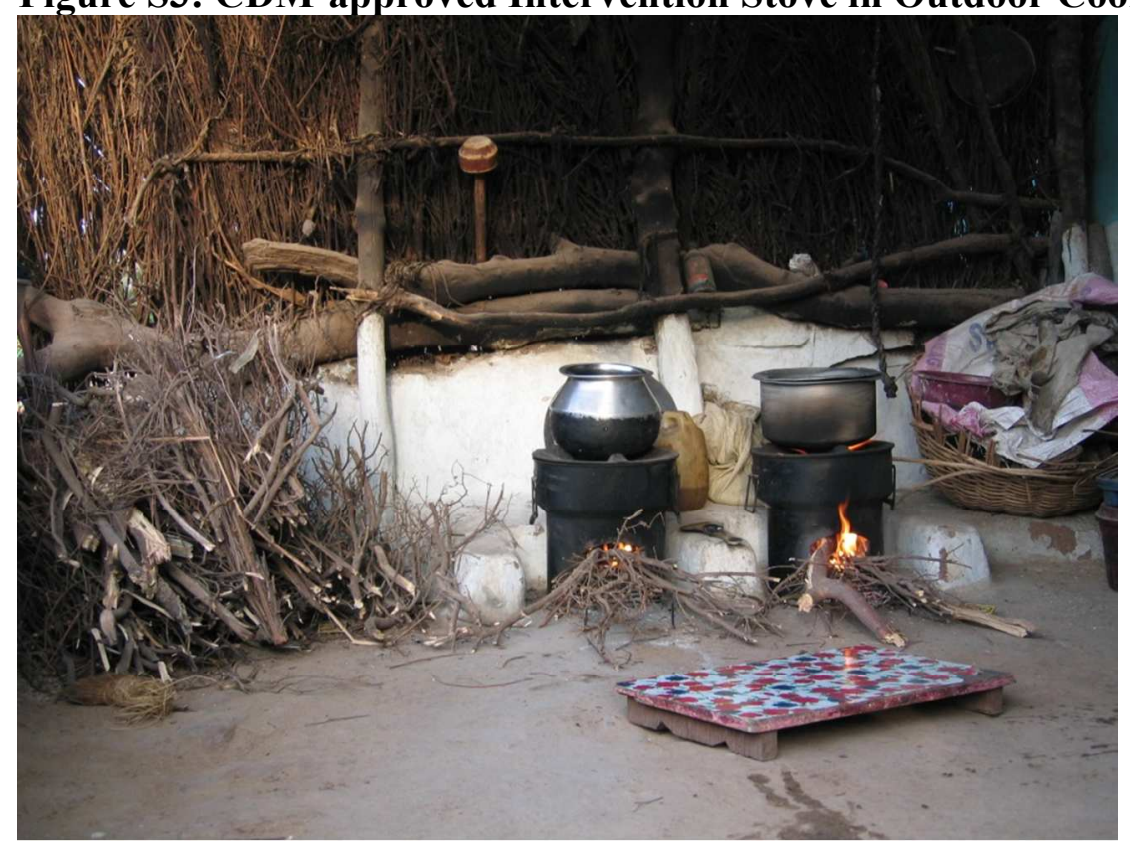

\section{SI 1: Carbon Crediting Methodology for the Karnataka Project}

According to the CDM methodology carbon credits are calculated from multiplying four key variables: 1) default value for net calorific value of the non-renewable woody biomass that is substituted $(0.015 \mathrm{TJ} /$ ton $) ; 2)$ default value for emissions for the substitution of non-renewable woody biomass (81.6 tCO2/TJ); 3) quantity of woody biomass saved; and 4) fraction of the wood savings which is non-renewable. ${ }^{1}$ Quantity of wood biomass saved was determined from a default efficiency value (0.1) and wood consumption of traditional stove versus efficiency of the intervention stove determined from laboratory-based Water Boiling Tests; wood savings were estimated to be $1.98 \mathrm{t} /$ household/year. Fraction of the wood savings that is non-renewable was determined from surveys, including Forest Survey of India, national and local statistics, maps, and remote sensing data resulting in a regional estimate of 0.953 . Values of the four variables above were multiplied to obtain project estimated emission reductions (carbon credits) of 2.31 tons of $\mathrm{CO}_{2}$-equivalent/household/year. ${ }^{2}$ 
Figure S4: Hire Waddarkal Village and Ambient Measurement Sites

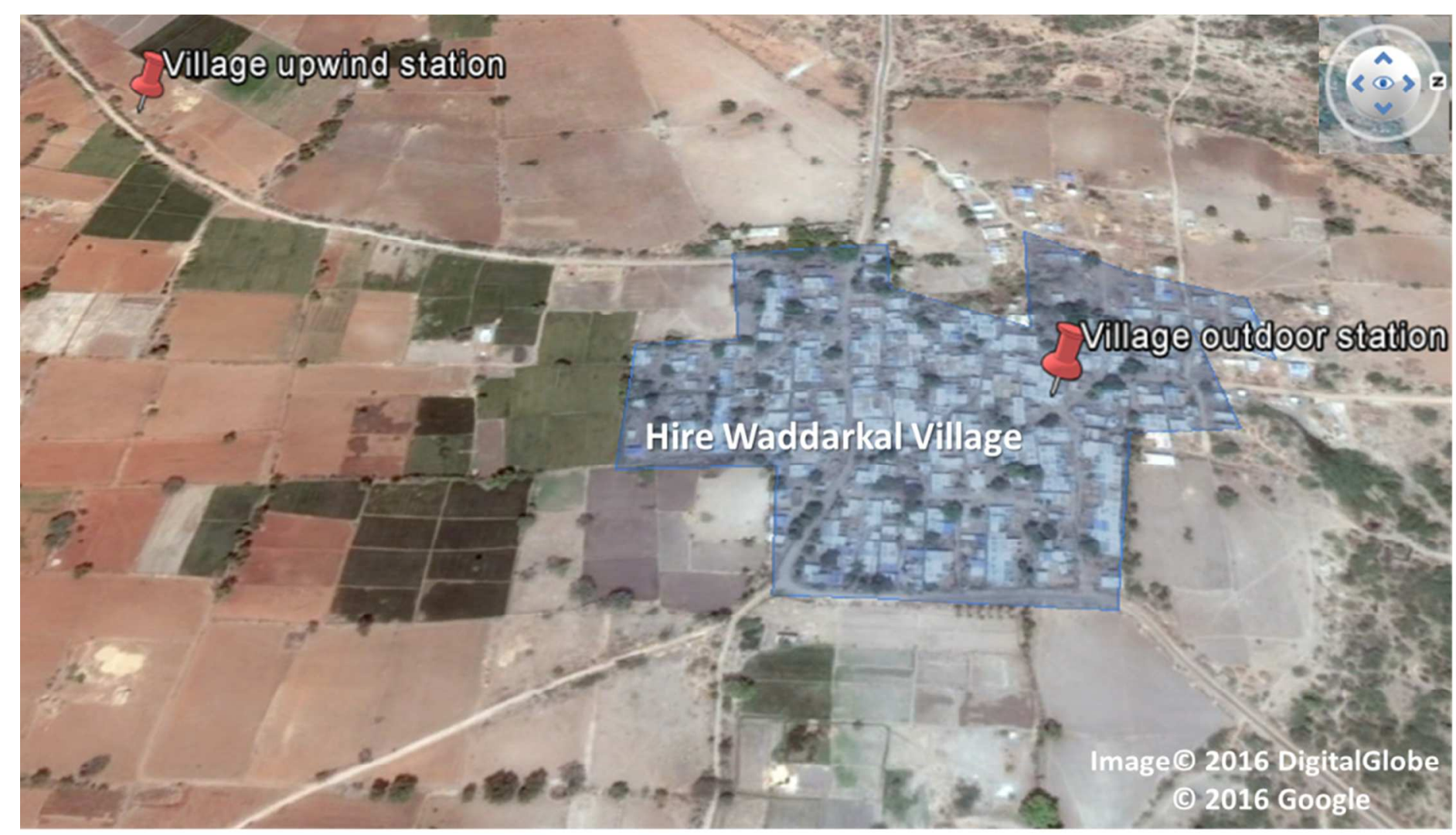


Figure S5: Study Design - Randomized Treatment with Control Population

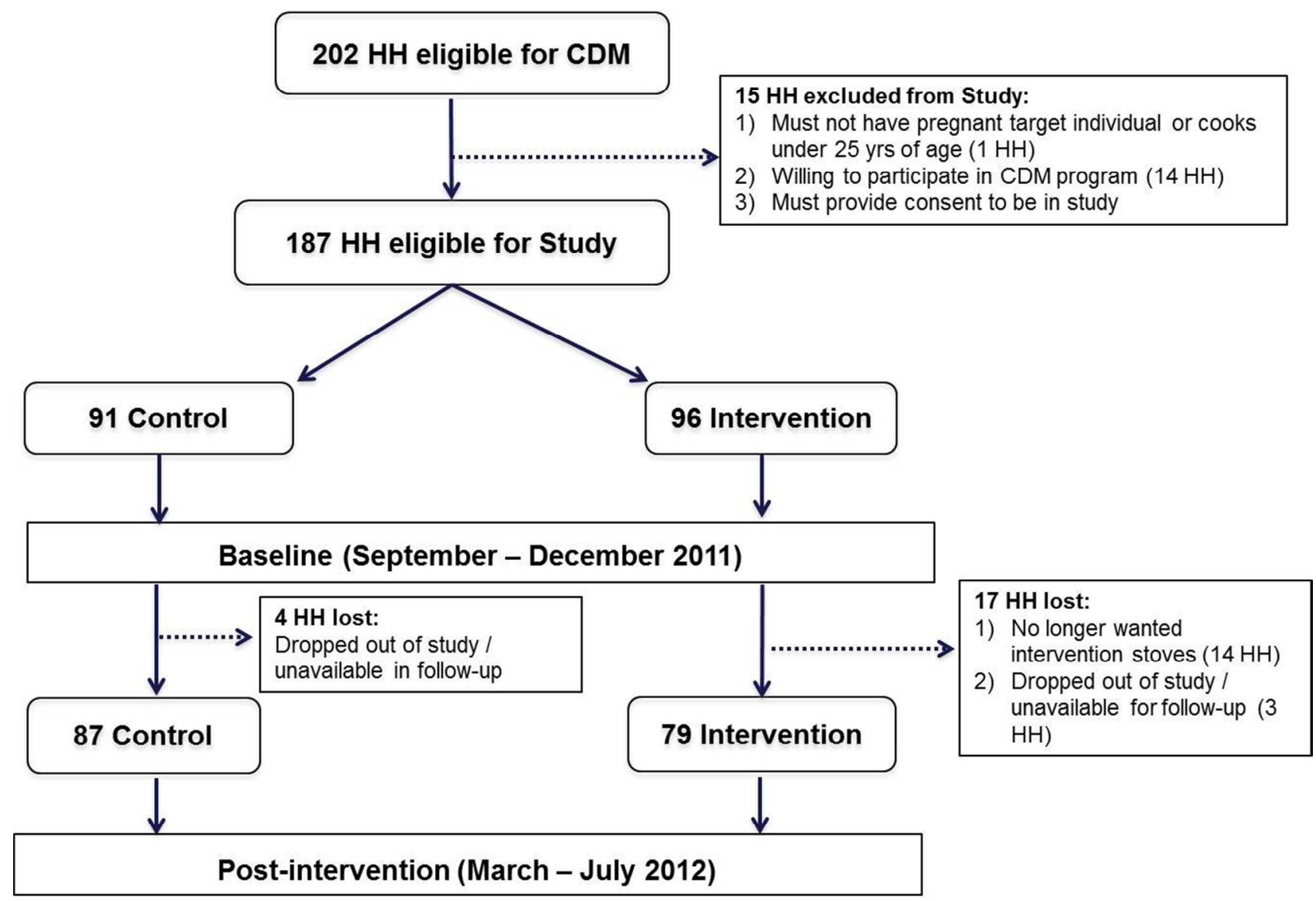

\section{SI 2: $\mathbf{P M}_{2.5}$ sampling}

$\mathrm{PM}_{2.5}$ samples were collected on $37 \mathrm{~mm}$ Teflon filters (EMD Millipore, MA, USA) placed downstream of a cyclone (GK2.05 (KTL) or GK2.05SH (KTL) (BGI Inc., Waltham, MA, USA)) with a $2.5 \mu \mathrm{m}$ aerodynamic-diameter cut point connected to a battery-operated pump (Apex Pro, Casella CEL, UK) running at $4.0 \pm 0.4 \mathrm{~L} \mathrm{~min}^{-1}$ for the GK2.05 cyclone and $3.5 \pm 0.35 \mathrm{~L} \mathrm{~min}^{-1}$ for the GK2.05SH cyclone. To prolong battery life, pumps were operated on duty cycles (1-min on, 1-min off [pre, early post phase]; 1-min on, 9-min off [remaining post]). 


\section{SI 3: Filter correction for shortened sampling durations}

In the post-intervention season, the indoor air pollution measurement period was shortened from 24 hours to 22 hours. The measurements were repeated in households where we failed to reach the 22-hr target measurement period due to equipment failure, and re-measured to ensure that at least two consecutive main meals or a minimum 16 hours in a day were captured. We assessed if there were statistically significant differences between PM measurements that ran for a full 24 hours and for shorter durations. To do this, 24-hour real-time data from DustTrak $\left(\mathrm{PM}_{2.5}\right)$ and microAeth $(\mathrm{BC})$ was used; the real-time monitoring was conducted in a subset of households $(n=30)$ co-located with the gravimetric measurements in both evaluation phases.

Of the total of 60 real-time measurements conducted during pre- and post-intervention seasons, $37 \mathrm{PM}_{2.5}$ and $46 \mathrm{BC}$ measurements completed a full 24- hour sampling period. These 24-hour sampling data were "shortened" and stratified into two types of measurement periods by taking either the first $>18-22$ hours ("short tail"; captured a brief non-cooking period after 2 main meals were cooked but did not complete 24-hours), or the first 16-18 hours ("cooking periods only"; captured 2 main meals but not the non-cooking period following the last meal) to simulate differences between filter measurements $<24$ hours, and evaluate the impact of losing data. Median air pollutant concentrations of the shortened measurement periods and the 24-hour measurement period were compared to test for differences. The short-tail samples ( $>18-22$-hour) were statistically significantly different $(\mathrm{p}<0.05)$ from the 24 -hour samples in $14 \mathrm{PM}_{2.5}$ and $5 \mathrm{BC}$ measurements. All of the two-peak samples (16-18 hour) were also statistically significantly different from the 24-hour sampling period. As a result, measurement periods where sampling captured a minimum of 2 consecutive main meals but did not meet the 24-hr target were adjusted 
to make them comparable to the 24-hour samples. Specifically, we applied correction factors drawn from distributions developed from co-located time-integrated and real-time $\mathrm{PM}_{2.5}$ (DustTrak) and BC (microAeth) indoor measurements. The number of measurement samples that were 22 hours or less was similar between control and intervention groups (Table S1).

Two types of "shortened" measurements:

1) "Short tail" - measurements captured two consecutive meals as well as a non-cooking period following the second meal, but did not complete the full 24-hour sampling period. Reasons for short-tail samples are either a result of an intended change from 24-hour to 22-hour sampling period in the latter half of the post-intervention season or due to equipment failure.

2) "Cooking periods only" - measurements that caught 2 consecutive main meals (16 hours - 18 hours) but did not sample non-cooking period following the second meal. The 16-18 hour division is based on real-time measurements in a subset of homes which showed that a range between 16 to 18 hours caught at least 2 consecutive meals (shown by two high peaks in air pollution concentrations) in households.

Of the 381 filter-based measurements, $43 \%$ completed a full 24 -hour target, $54 \%$ completed $>18$ 23 hours ("short-tail"), and 4\% captured 16-18 hours ("cooking periods only") (Table S1). 
Table S1: Filter Counts and Sampling Duration by Measurement Season and Randomized

\section{Groups}

\begin{tabular}{|c|c|c|c|c|}
\hline & $\begin{array}{c}\text { Cooking periods } \\
\text { only } \\
\text { (16 hrs - } 18 \text { hrs) }\end{array}$ & $\begin{array}{c}\text { Short tail } \\
>18-23 \mathrm{hrs}\end{array}$ & $\begin{array}{l}\text { Full cycle } \\
24 \text { hrs }\end{array}$ & TOTAL \\
\hline \multicolumn{5}{|l|}{ By Season } \\
\hline $\begin{array}{l}\text { Season } 1 \\
(1: 1 \mathrm{~min} \text { on/off })\end{array}$ & 6 & 35 & 148 & 189 \\
\hline $\begin{array}{l}\text { Season } 2 \\
(1: 1 \mathrm{~min} \text { on/off) } \\
\text { Season } 2.1 \\
(1: 9 \mathrm{~min} \text { on/off })\end{array}$ & 8 & 169 & 15 & 192 \\
\hline TOTAL & $\begin{array}{c}14 \\
(4 \%)\end{array}$ & $\begin{array}{c}204 \\
(54 \%)\end{array}$ & $\begin{array}{c}163 \\
(43 \%)\end{array}$ & 381 \\
\hline \multicolumn{5}{|l|}{ By randomized groups } \\
\hline $\begin{array}{l}\text { Control } \\
\text { (percent of total filters) }\end{array}$ & $\begin{array}{c}6 \\
(3 \%)\end{array}$ & $\begin{array}{c}108 \\
(57 \%)\end{array}$ & $\begin{array}{c}75 \\
(40 \%)\end{array}$ & 189 \\
\hline $\begin{array}{l}\text { Intervention } \\
\text { (percent of total filters) }\end{array}$ & $\begin{array}{c}8 \\
(4 \%)\end{array}$ & $\begin{array}{c}96 \\
(50 \%)\end{array}$ & $\begin{array}{c}88 \\
(46 \%)\end{array}$ & 192 \\
\hline
\end{tabular}

Method:

Linear-regression fits based on the 24-hour average filter concentrations with paired and colocated real-time monitors for $\mathrm{PM}_{2.5}$ (DustTrak (DT)) and black carbon (MicroAeth) were used to correct 'short' filter-based concentrations grouped under those that had a "short tail" (>18 - 23 hours), and those that stopped immediately after sampling 2 main consecutive meals, "cooking periods only" (16-18 hours). The raw DT concentrations were not normalized because in this case, we were only interested in the relationship between DT and filter concentration and not the absolute values. 
Step 1: Samples where filters and real-time monitors (DT and microAeth) ran the same sampling duration were matched to develop a regression between gravimetric concentrations and real-time measurements. Linear regression fits between 24-hour filter and real-time DT (PM) and microAeth (BC) concentrations provided $\mathrm{R}^{2}$ values of $\sim 0.6-0.8$ (Figure $\mathrm{S6-S9}$ ).

Step 2: The regression equations were applied to co-located air sampling measurements where filters run short of the 24-hour sampling duration but where real-time (DT and microAeth) 24hour sampling was completed.

For example, the regressions equation for $\mathrm{PM}_{2.5}$ (between shortened filter-based and 24-hour DustTrak concentrations) in Season 1 (Baseline) is:

$$
y=0.1976 x-37.756
$$

where $x$ is 24-hour mean concentration of $\mathrm{PM}_{2.5}$ from real-time DT monitor, and $y$ is expected filter concentration from a 24-hour sampling.

A concentration value from the "shortened" filter concentration (either "short-tail" or "cooking periods only" samples) was divided by the expected filter concentration to obtain an adjustment ratio as summarized in Table $\mathrm{S} 2$ for $\mathrm{PM}_{2.5}$ and absorbance (for breakdown by season and more details see Table S3-S4).

Step 3: To adjust the shortened filters and propagate uncertainty throughout the correction process, a value was drawn from a normal distribution represented by the ratios as the mean and SD was applied to the "shortened" filters that run less than 24 hours. 
Table S2: Summary of Filter versus Real-time Linear Regression Fits and Adjustment ratios Shortened Sampling Durations

\begin{tabular}{|c|c|c|c|c|}
\hline \multirow{2}{*}{ Comparison } & \multicolumn{2}{|c|}{ Linear-Regression Fits } & \multirow{2}{*}{$\begin{array}{l}\text { Mean (SD) ratios for } \\
>18-23 \text { hour sampling } \\
\text { filters }\end{array}$} & \multirow{2}{*}{$\begin{array}{l}\text { Mean (SD) ratios for } \\
16-18 \text { hour sampling } \\
\text { filters }\end{array}$} \\
\hline & Season 1 & Season 2 & & \\
\hline $\begin{array}{l}\text { Filter mass and Real- } \\
\text { time } \mathrm{PM}_{2.5}\end{array}$ & $\begin{array}{l}y=0.1976 x-37.756 \\
\left(\mathrm{R}^{2}=0.8762\right)\end{array}$ & $\begin{array}{l}y=0.3445 x+28.044 \\
\left(R^{2}=0.8159\right)\end{array}$ & $1.02(0.15)$ & $1.37(0.58)$ \\
\hline $\begin{array}{l}\text { Filter absorbance and } \\
\text { real-time BC }\end{array}$ & $\begin{array}{l}y=0.6258 x+4.0264 \\
\left(R^{2}=0.6537\right)\end{array}$ & $\begin{array}{l}y=7.912 x+7.2733 \\
\left(R^{2}=0.7425\right)\end{array}$ & $0.94(0.22)$ & $0.43(0.11)$ \\
\hline
\end{tabular}


Figure S6: 24-hr Filter vs. Real-Time PM (Baseline 1)

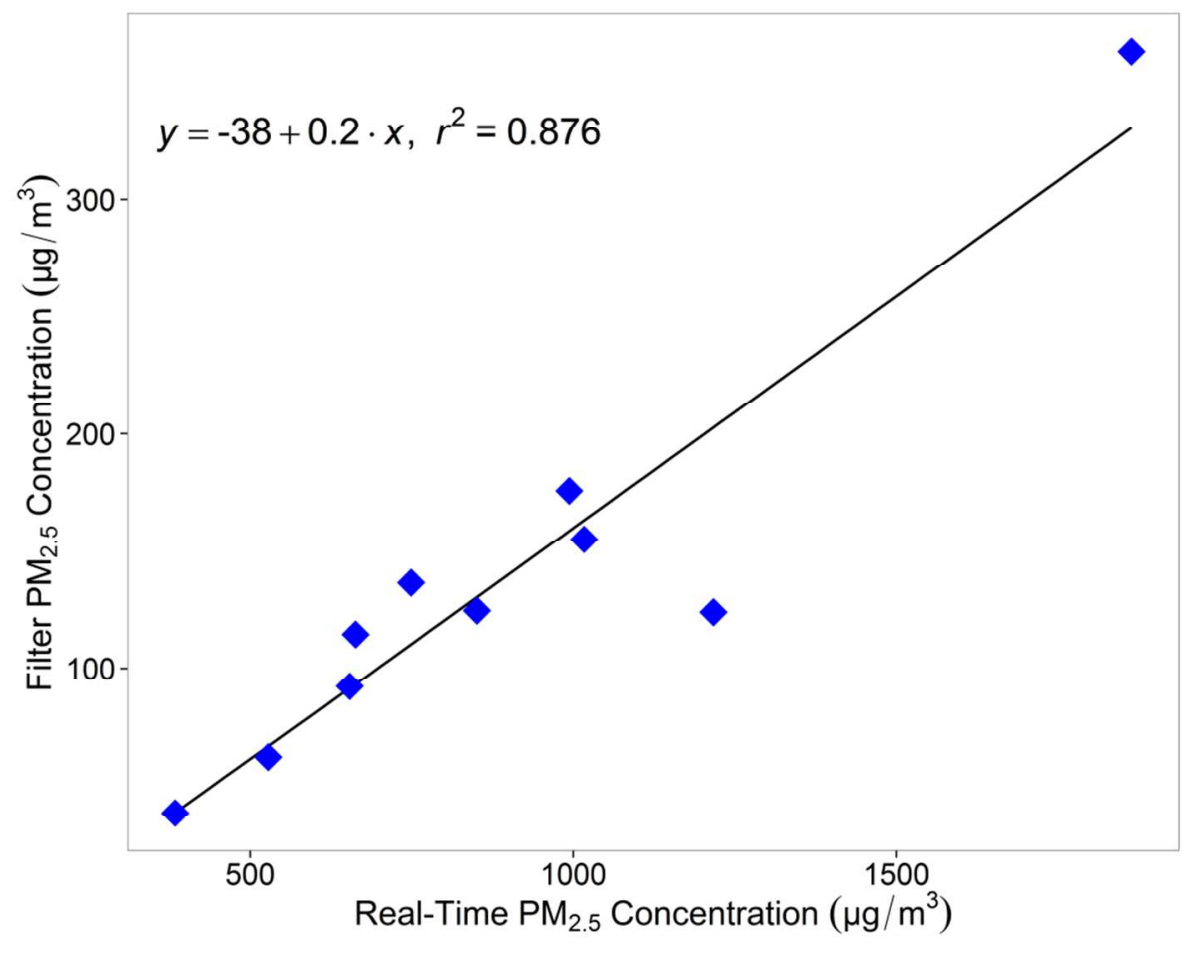

Figure S7: 24-hr Filter vs. Real-Time BC (Baseline)

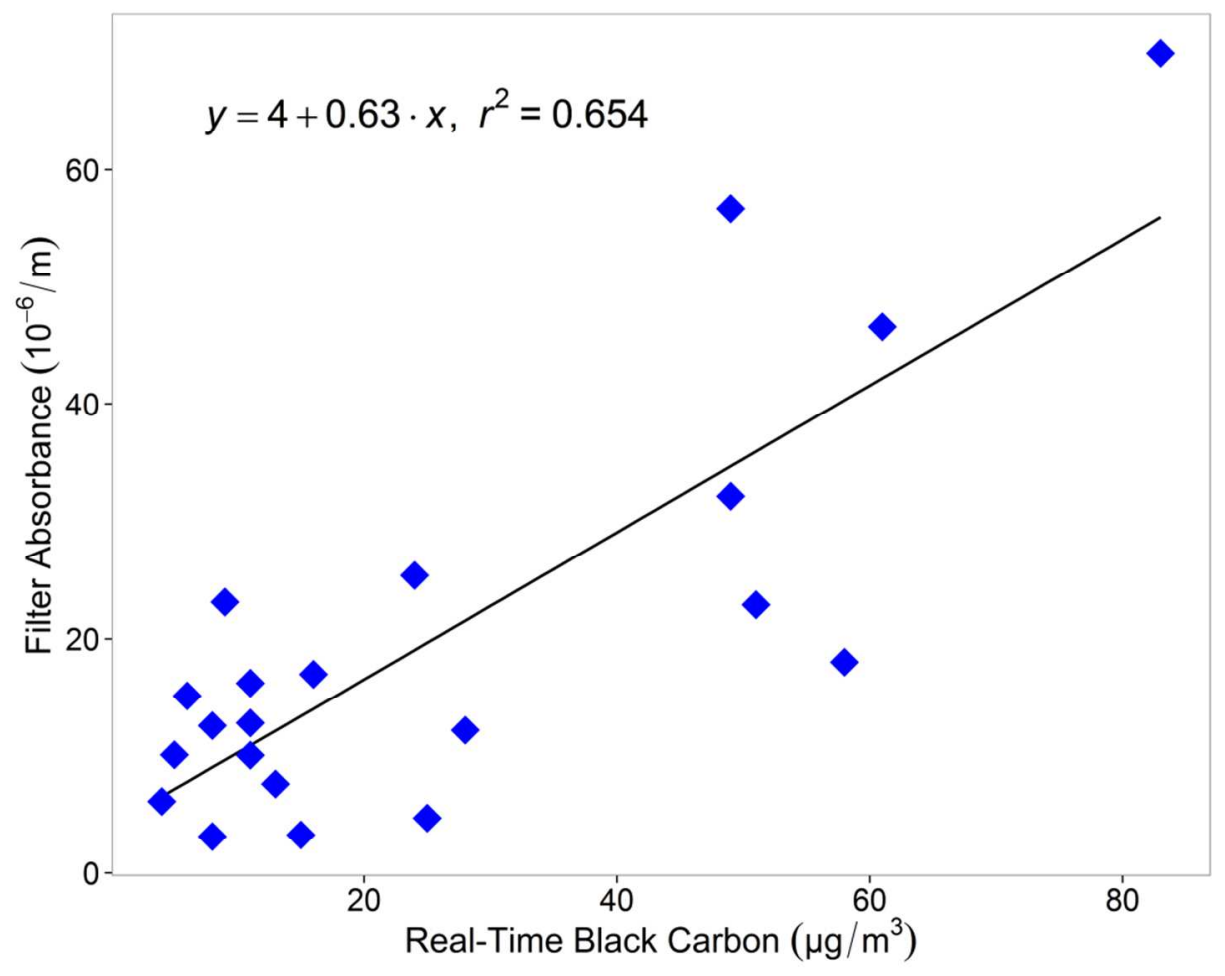


Figure S8: 24-hr Filter vs. Real-Time PM (Post-Intervention)

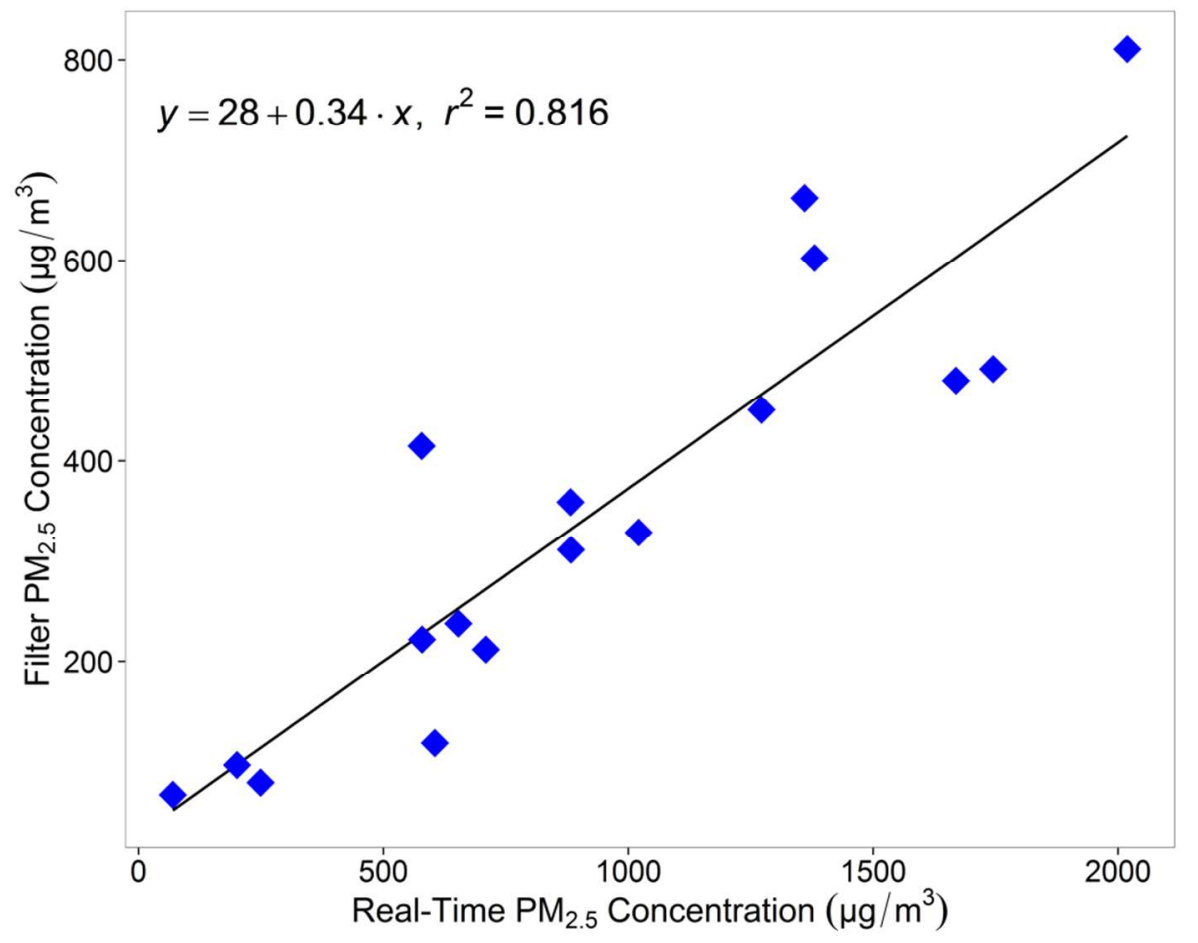

Figure S9: 24-hr Filter vs. Real-Time BC (Post-Intervention)

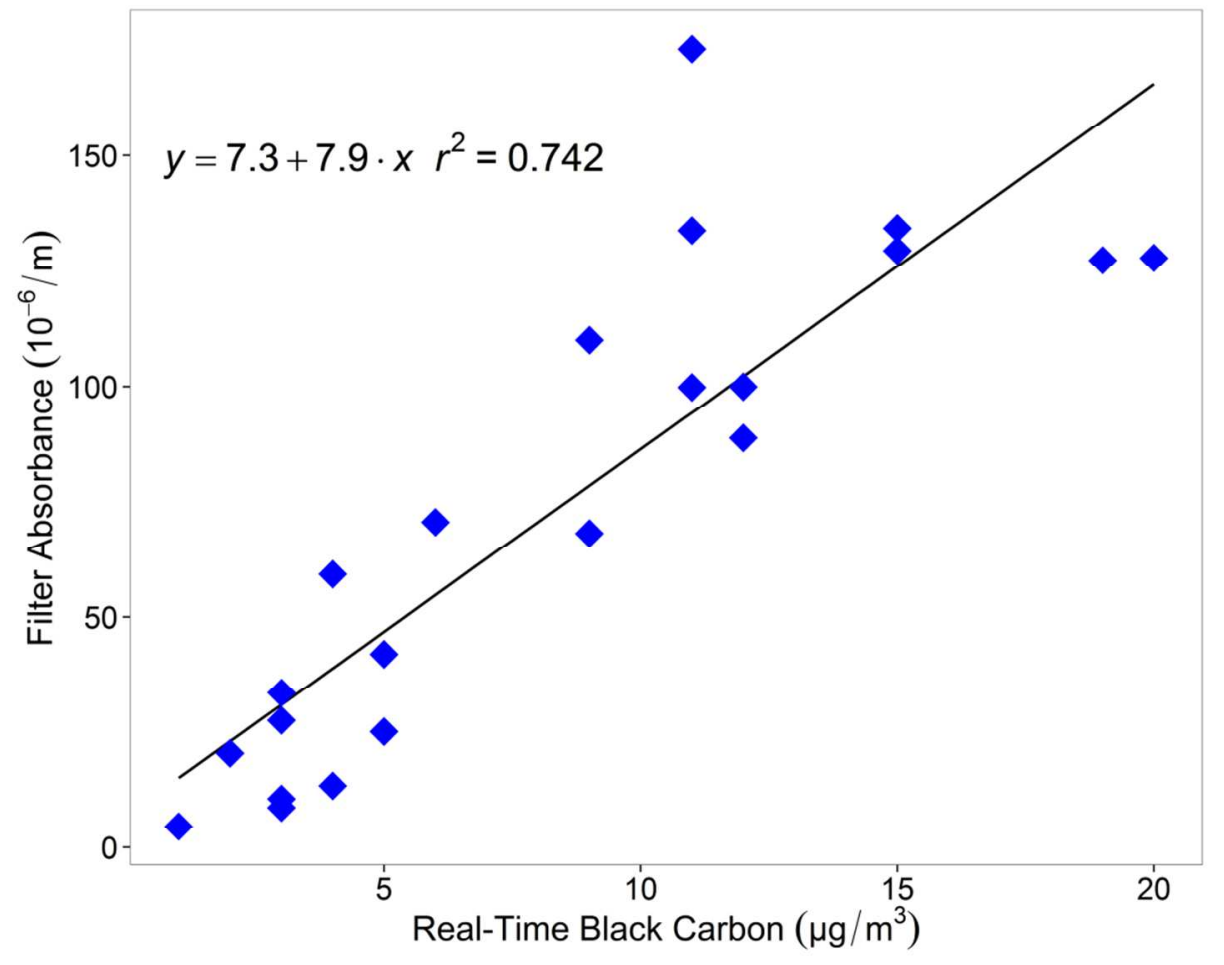


Table S3: PM 2.5 Adjustment Ratios

\section{Baseline (Season 1)}

$y=0.1976 x-37.756\left(R^{2}=0.8762\right)$

\begin{tabular}{|c|c|c|c|c|c|c|c|c|c|}
\hline Season & $\begin{array}{l}\text { Sample } \\
\text { duration }\end{array}$ & $\begin{array}{c}\mathrm{X} \\
\text { (DustTrak } \\
\text { PM) }\end{array}$ & Slope & Intercept & $\begin{array}{c}\text { Y } \\
\text { (Expected } \\
\text { concentration) }\end{array}$ & $\begin{array}{c}\text { Actual filter } \\
\text { concentration } \\
(u g / m 3)\end{array}$ & $\begin{array}{c}\text { Ratio } \\
\text { (Actual/Expected) } \\
\text { reading }\end{array}$ & $\begin{array}{c}\text { Mean Ratios } \\
\text { (Season } 1 \text { and 2) }\end{array}$ & SD \\
\hline
\end{tabular}

Filters $>18-22$ hours ("short-tail")

$\begin{array}{rrrrrrrr}1 & 18-22 \mathrm{hrs} & 384 & 0.1976 & 37.756 & 38 & 37.83 & 0.99 \\ 1 & 18-22 \mathrm{hrs} & 1390 & 0.1976 & 37.756 & 237 & 290.57 & 1.23 \\ 1 & 18-22 \mathrm{hrs} & 1269 & 0.1976 & 37.756 & 213 & 206.51 & 0.97 \\ 2 & 18-22 \mathrm{hrs} & 934 & 0.3445 & 28.044 & 350 & 308.46 & 0.88\end{array}$

Filters 16-18 hours ("cooking periods only")

$\begin{array}{rrrrrrrr}1 & 2 \text { meals } & 580 & 0.1976 & 37.756 & 77 & 134.64 & 1.75 \\ 1 & 2 \text { meals } & 1133 & 0.1976 & 37.756 & 186 & 288.44 & 1.55 \\ 1 & 2 \text { meals } & 605 & 0.1976 & 37.756 & 82 & 42.20 & 0.52 \\ 1 & 2 \text { meals } & 399 & 0.1976 & 37.756 & 41 & 68.52 & 1.67\end{array}$


Table S4: Absorbance Adjustment Ratios

\section{Baseline (Season 1)}

$y=0.6258 x+4.0264\left(R^{2}=0.6537\right)$

\begin{tabular}{|c|c|c|c|c|c|c|c|c|c|}
\hline Season & $\begin{array}{l}\text { Sample } \\
\text { duration }\end{array}$ & $\begin{array}{c}\text { AETH } \\
\text { BC }\end{array}$ & Slope & Intercept & $\begin{array}{c}\text { Y } \\
\text { (Expected } \\
\text { absorbance) }\end{array}$ & $\begin{array}{l}\text { Actual } \\
\text { filter Abs } \\
\left(10^{\wedge}-6 / m\right)\end{array}$ & $\begin{array}{c}\text { Ratio } \\
\text { (Actual/Expected) } \\
\text { reading }\end{array}$ & $\begin{array}{c}\text { Mean ratios } \\
\text { (Season } 1 \text { and 2) }\end{array}$ & SD \\
\hline
\end{tabular}

\section{Filters >18-22 hours ("short-tail")}

$\begin{array}{cccccccc}1 & 18-22 \mathrm{hrs} & 41 & 0.6258 & 4.0264 & 30 & 32.14 & 1.08 \\ 1 & 18-22 \mathrm{hrs} & 22 & 0.6258 & 4.0264 & 18 & 12.2 & 0.69 \\ 2 & 18-22 \mathrm{hrs} & 15 & 7.912 & 7.2733 & 126 & 134.22 & 1.07\end{array}$

\begin{tabular}{|c|c|c|c|c|c|c|c|c|c|}
\hline & & & & & & & & 0.94 & 0.22 \\
\hline \multicolumn{10}{|c|}{ Filters 16-18 hours ("cooking periods only") } \\
\hline 1 & 2 meals & 46 & 0.6258 & 4.0264 & 33 & 18.02 & 0.55 & & \\
\hline 1 & 2 meals & 9 & 0.6258 & 4.0264 & 10 & 3.1 & 0.32 & & \\
\hline \multirow[t]{2}{*}{2} & 2 meals & 3 & 7.912 & 7.2733 & 31 & 13.43 & 0.43 & & \\
\hline & & & & & & & & 0.43 & 0.11 \\
\hline
\end{tabular}




\section{SI 4: Teflon Filter Laboratory Analysis}

The $37 \mathrm{~mm}$ Teflon filters were pre- and post-weighed in triplicate on a microbalance (Sartorius M3P) at the University of Minnesota (7\% of study filters) and the School of Population and Public Health at the University of British Columbia (93\% of filters). To ensure consistency in quality of balances and environment between the two laboratories, five filters were weighed at both labs; differences were less than or equal to $0.02 \mathrm{mg}$ for each filter.

Prior to weighing, filters were allowed to equilibrate in a temperature and humidity controlled room for at least 48 hours $\left(21^{\circ} \mathrm{C} \pm 2{ }^{\circ} \mathrm{C} ; 40 \pm 5 \%\right)$. A radioactive neutralizer was used to remove static charge and filters were reweighed if three consecutive weights of the same filter were not within $0.01 \mathrm{mg}$ of one another.

Three laboratory blanks were kept in the balance room for use as quality control, and were weighed at the beginning and end of each weighing session. A total of 49 field blanks were deployed in the field with a mean (SD) mass gain of $0.004 \mathrm{mg}(0.009)$ over the two measurement phases. Blank correction was performed by subtracting the mean mass of field blanks from the mass of the $\mathrm{PM}_{2.5}$ filter samples. The $\mathrm{PM}_{2.5}$ mass concentration was obtained by dividing the blank-corrected mass by the sampled air volume. 
RESULT SECTION

Table S5: Baseline Characteristics of Participating and Drop-out Households

\begin{tabular}{|c|c|c|c|c|c|c|c|c|}
\hline Characteristics & $\begin{array}{l}\text { Control } \\
(\mathrm{n}=91)\end{array}$ & $\begin{array}{l}\text { Intervention } \\
\quad(\mathrm{n}=96)\end{array}$ & $\begin{array}{c}\text { p- } \\
\text { value }^{a}\end{array}$ & $\begin{array}{l}\text { Drop out } \\
(\mathrm{n}=21)\end{array}$ & $\begin{array}{c}\mathrm{p}- \\
\text { value }^{\mathrm{b}}\end{array}$ & $\begin{array}{l}\text { Control- } \\
\text { after drop } \\
\text { out } \\
(\mathrm{n}=87)\end{array}$ & $\begin{array}{l}\text { Intervention- } \\
\text { after drop out } \\
\quad(\mathrm{n}=79)\end{array}$ & $\begin{array}{c}\mathrm{p}- \\
\text { value }^{\mathrm{c}}\end{array}$ \\
\hline $\begin{array}{l}\text { Number of rooms } \\
\text { in house }\end{array}$ & $2.0 \pm 1.0$ & $2.2 \pm 1.1$ & 0.19 & $2.0 \pm 0.8$ & 0.82 & $2.0 \pm 1.0$ & $2.3 \pm 1.2$ & 0.14 \\
\hline Family size & $6.1 \pm 1.9$ & $5.8 \pm 2.0$ & 0.35 & $5.7 \pm 1.6$ & 0.43 & $6.1 \pm 2.0$ & $5.8 \pm 2.0$ & 0.30 \\
\hline $\begin{array}{l}\text { House type (shared } \\
\text { wall with } \\
\text { neighbor) }(\%)\end{array}$ & 83 & 84 & 0.95 & 95 & 0.22 & 82 & 82 & 1.00 \\
\hline $\begin{array}{l}\text { Roof Material } \\
\text { (improved, i.e. } \\
\text { corrugated iron, } \\
\text { zinc, metal sheets, } \\
\text { cement, concrete, } \\
\text { tiles) }(\%)\end{array}$ & 53 & 52 & 1.00 & 57 & 0.82 & 52 & 52 & 1.00 \\
\hline $\begin{array}{l}\text { Floor Material } \\
\text { (finished floor, i.e. } \\
\text { ceramic, marble } \\
\text { tiles, } \\
\text { cement/concrete, } \\
\text { stone) (\%) }\end{array}$ & 67 & 75 & 0.30 & 71 & 1.00 & 68 & 75 & 0.42 \\
\hline $\begin{array}{l}\text { Area of irrigated } \\
\text { land owned }\end{array}$ & $1.8 \pm 2.8$ & $1.6 \pm 2.8$ & 0.42 & $1.7 \pm 2.6$ & 0.85 & $1.9 \pm 2.8$ & $1.5 \pm 2.8$ & 0.17 \\
\hline Radio (\%) & 12 & 5 & 0.16 & 5 & 0.81 & 13 & 5 & 0.15 \\
\hline TV (\%) & 20 & 28 & 0.24 & 24 & 1.00 & 21 & 28 & 0.37 \\
\hline Bicycle (\%) & 16 & 20 & 0.71 & 10 & 0.36 & 18 & 23 & 0.61 \\
\hline Motorcycle (\%) & 12 & 9 & 0.72 & 14 & 0.86 & 13 & 8 & 0.42 \\
\hline Electric mixer (\%) & 8 & 9 & 0.88 & 10 & 1.00 & 8 & 9 & 1.00 \\
\hline $\begin{array}{l}\text { Cow ownership } \\
(\%)\end{array}$ & 36 & 45 & 0.30 & 57 & 0.16 & 37 & 41 & 0.74 \\
\hline $\begin{array}{l}\text { Buffalo ownership } \\
(\%)\end{array}$ & 18 & 11 & 0.33 & 14 & 1.00 & 18 & 10 & 0.20 \\
\hline $\begin{array}{l}\text { Chimney above } \\
\text { stove }(\%)\end{array}$ & 36 & 39 & 0.79 & 43 & 0.80 & 37 & 38 & 1.00 \\
\hline $\begin{array}{l}\text { Smokers in home } \\
(\%)\end{array}$ & 36 & 36 & 1.00 & 35 & 1.00 & 35 & 37 & 0.93 \\
\hline No windows (\%) & 27 & 26 & 0.95 & 16 & 0.40 & 28 & 27 & 1.00 \\
\hline
\end{tabular}


Data are mean $\pm S D$ or number (\%). p-Values are two-tailed t-tests for continuous variables; chi-square tests for categorical variables.

${ }^{a}$ Between control and intervention groups as randomized.

${ }^{\mathrm{b}}$ Between drop out group and study population that remained in the study.

${ }^{\mathrm{c}}$ Between control and intervention groups that remained until end of the study.

Table S6: Change in Fuelwood Use by Season and Stove Use Groups

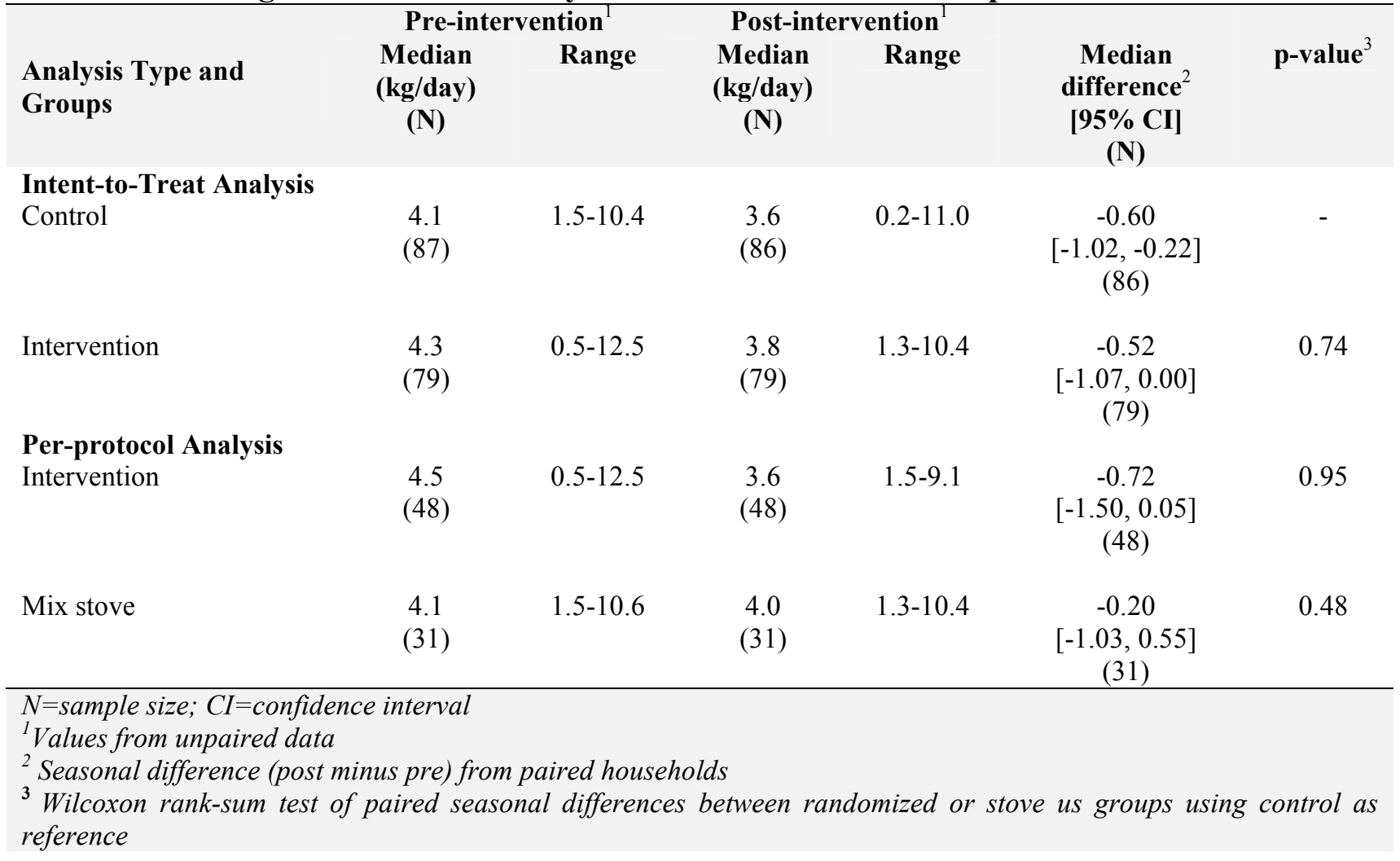


Figure S10: Change in 24-hour Fuelwood Consumption by Stove Use

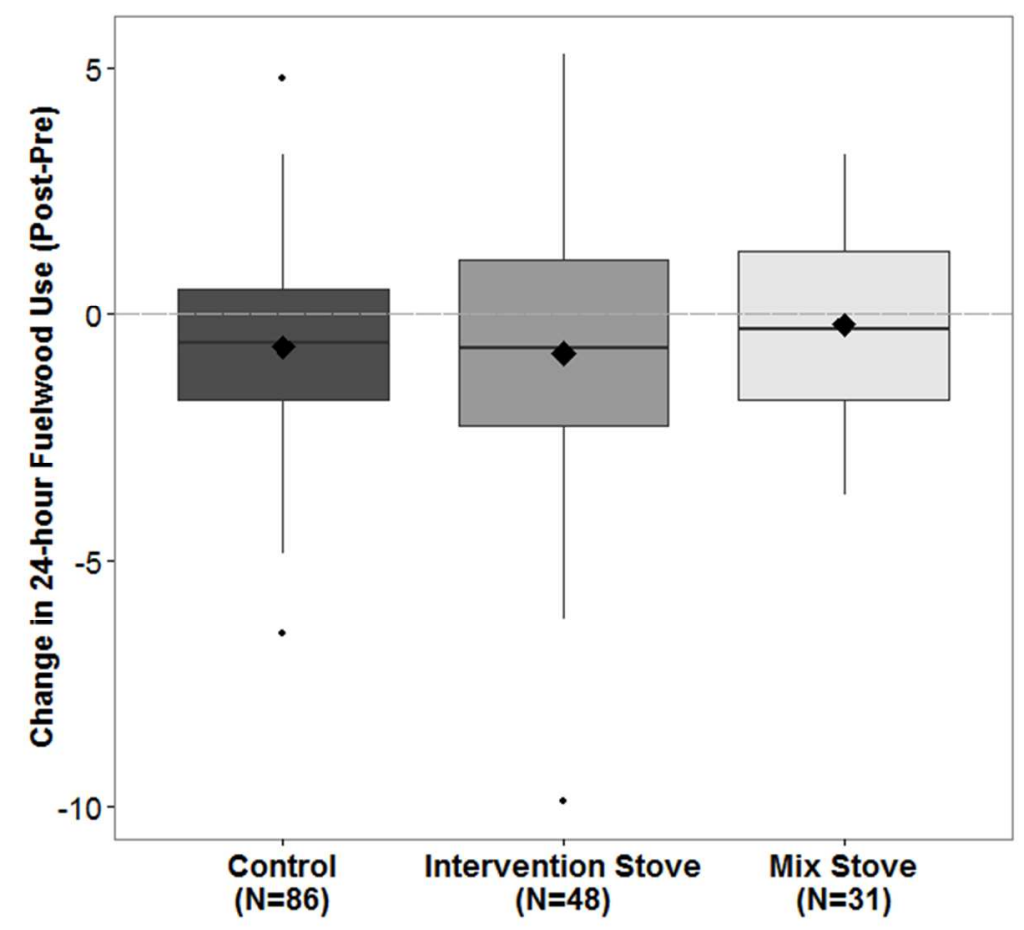

Median and mean are represented by black horizontal line and diamond symbol, respectively.

\section{SI 5: Fuelwood Moisture}

The moisture content of weighed fuelwood corresponded with seasonal conditions, and was moderately higher $(\mathrm{p}<0.01)$ pre-intervention (post-monsoon/winter) compared to postintervention (summer) (mean (SD) among all households: 15\% (5\%) [pre] and 11\% (3\%) [post]. The decrease in fuelwood moisture in the post-intervention season may be responsible for the reduced fuelwood consumption in that season, owing to more efficient burning of drier wood. The seasonal decrease (post - pre) in median fuelwood moisture content did not differ between control $(-4.0 \%)$ and exclusive intervention stove $(-3.8 \%)$ homes, but decreases for mixed stove homes $(-4.8 \%)$ were marginally greater $(p=0.10)$ than the control group. 
Table S7: Weather Conditions, and 24-hour $\mathbf{P M}_{2.5}$ and Absorbance Concentrations Upwind and Center of Village during Pre- and Post-Intervention Seasons

\begin{tabular}{|c|c|c|c|c|c|c|c|c|}
\hline \multirow[b]{2}{*}{ Season } & \multirow{2}{*}{$\begin{array}{c}\text { Mean } \\
\text { (SD) } \\
\text { Tempera } \\
\text {-ture } \\
\left({ }^{\circ} \mathbf{C}\right)\end{array}$} & \multirow{2}{*}{$\begin{array}{c}\text { Mean } \\
\text { (SD) } \\
\text { Humidity } \\
\text { (\%) }\end{array}$} & \multicolumn{2}{|c|}{$\begin{array}{l}\text { Upwind Village } \\
\text { Mean (SD) }\end{array}$} & \multicolumn{2}{|c|}{$\begin{array}{l}\text { Center Village } \\
\text { Mean (SD) }\end{array}$} & \multirow{2}{*}{$\begin{array}{c}\text { Upwind \& } \\
\text { Center } \\
\text { Village } \\
\text { Difference } \\
(95 \% \text { CI) } \\
\text { PM }_{2.5} \\
\left(\mu \mathrm{g} / \mathbf{m}^{3}\right)\end{array}$} & \multirow{2}{*}{$\begin{array}{c}\text { Upwind \& } \\
\text { Center } \\
\text { Village } \\
\text { Difference } \\
(95 \% \text { CI) } \\
\text { Abs } \\
\left(10^{-6} / \mathrm{m}\right)\end{array}$} \\
\hline & & & $\begin{array}{c}\mathrm{PM}_{2.5} \\
\left(\mu \mathrm{g} / \mathrm{m}^{3}\right)\end{array}$ & $\underset{\left(10^{-6} / \mathrm{m}\right)}{\operatorname{Abs}}$ & $\begin{array}{r}\mathrm{PM}_{2.5} \\
\left(\mu \mathrm{g} / \mathrm{m}^{3}\right)\end{array}$ & $\begin{array}{c}\text { Abs } \\
\left(10^{-6} / \mathrm{m}\right)\end{array}$ & & \\
\hline $\begin{array}{l}\text { Pre- } \\
\text { intervention }^{\mathrm{a}}\end{array}$ & $26(2)$ & $63(11)$ & $\begin{array}{l}4(3.1) \\
(n=8)\end{array}$ & $\begin{array}{c}0.3(0.3) \\
(\mathrm{n}=7)\end{array}$ & $\begin{array}{l}23(15) \\
(\mathrm{n}=38)\end{array}$ & $\begin{array}{c}3.3(2.1) \\
(\mathrm{n}=38)\end{array}$ & $\begin{array}{c}13 \\
(8,24)\end{array}$ & $\begin{array}{c}2.7 \\
(1.4,3.9)\end{array}$ \\
\hline $\begin{array}{l}\text { Post- } \\
\text { intervention }^{a}\end{array}$ & $30(3)$ & $52(17)$ & $\begin{array}{l}5(0.5) \\
(\mathrm{n}=2)\end{array}$ & $\begin{array}{c}1.2(0.9) \\
(\mathrm{n}=8)\end{array}$ & $\begin{array}{l}29(23) \\
(\mathrm{n}=36)\end{array}$ & $\begin{array}{l}3.2(2.2) \\
(\mathrm{n}=35)\end{array}$ & $\begin{array}{c}18 \\
(-1,62)\end{array}$ & $\begin{array}{c}1.6 \\
(0.5,2.9)\end{array}$ \\
\hline \multicolumn{9}{|c|}{$\begin{array}{l}\text { SD }=\text { Standard Deviation; } n=\text { sample size; } C I=\text { confidence interval } \\
\left.{ }^{a} \text { Pre-intervention (September 2-28, 2011); Post-intervention (July } 14-\text { August } 4\right) \\
{ }^{b} \text { Wilcoxon rank-sum test for difference and } 95 \% \text { CI between upwind and center of village concentrations }\end{array}$} \\
\hline
\end{tabular}

\section{SI 6: Regional and Village-Level Ambient Concentrations}

Of the $88 \mathrm{PM}_{2.5}$ samples collected in the village center, 73 were analyzed for mass and absorbance upon meeting minimum flow rate and volume criteria, and having non-negative filter mass. Of the 27 PM samples collected upwind of the village, 10 were analyzed for mass and 15 were analyzed for absorbance; the remaining samples were excluded owing to unstable flow rate and negative measurement of filter mass. Negative filter masses were presumably a result of low ambient concentrations and low pump flow rates, particularly in the post-intervention season, because of the reduced sampling duty cycle. Results of these filter analyses are presented in Table S7. 


\section{Figure S11: Ambient 30-min Average $\mathbf{P M}_{2.5}$ Concentrations at Center of Village}

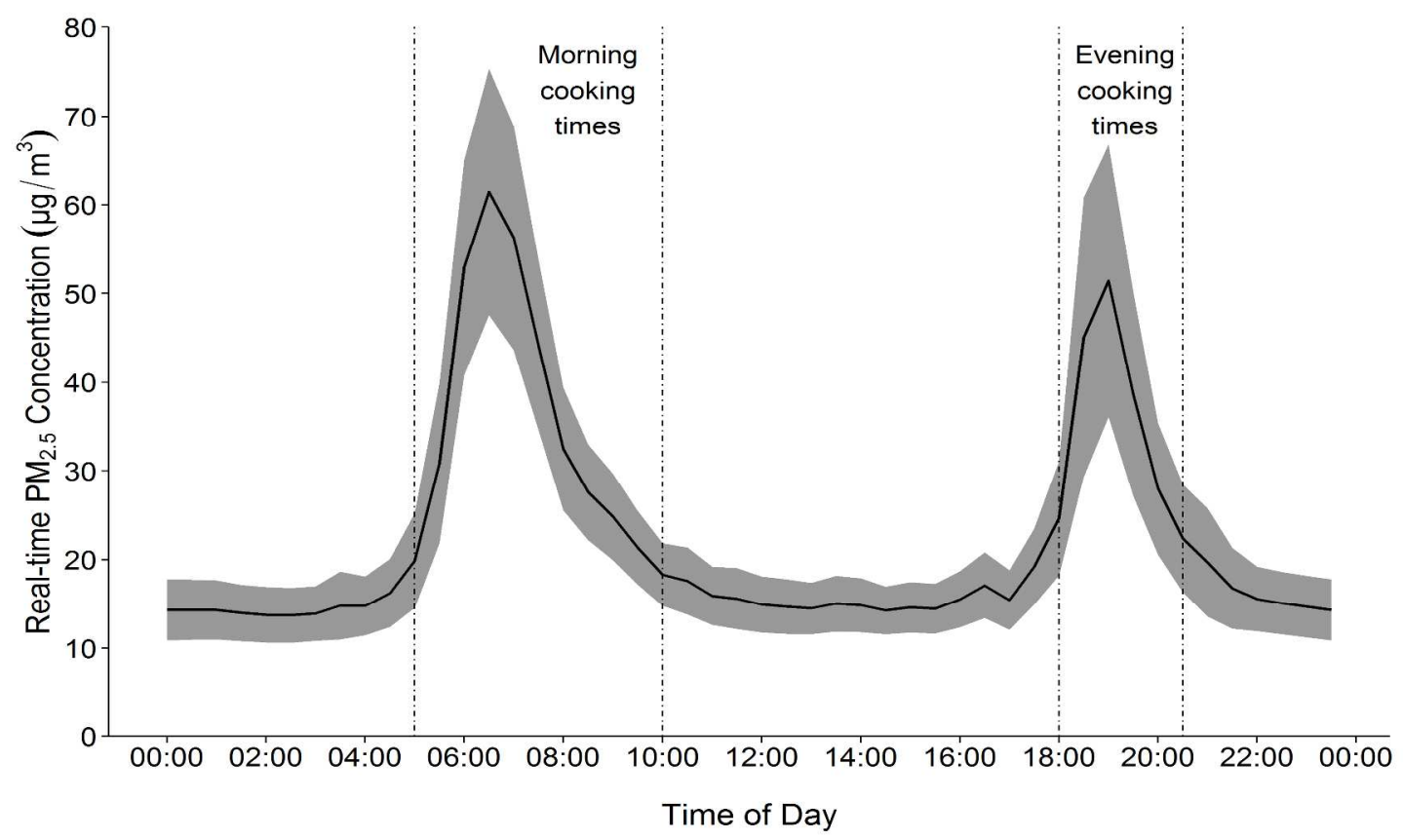

From DustTrak PM..5 measurements located at center of village during baseline season (September 10, 2011 December 10, 2011) over 37 measurement days. Shaded areas represent $95 \%$ confidence intervals.

Figure S11 is derived from DustTrak (DT) data adjusted with co-located integrated filter measurement. We normalized the DT data by first obtaining a ratio by dividing co-located 24hour filter concentration by mean of the 24-hour DT concentration. The ratio was then multiplied with the 30-minute average DT data. Similar to Rehman et al., ${ }^{3}$ our study found significant contributions of indoor biomass combustion activities to ambient village concentrations particularly during morning and evening cooking times.

\section{SI 7: Repeated Household Measures to Assess Day-to-Day Variability}

Of the total 40 households that had repeated indoor air pollution measurements in baseline and post-intervention seasons to assess day-to-day variability, 16 completed three consecutive sampling days and 13 completed two consecutive sampling days; the remaining households were 
excluded from analysis because follow-up measurements did not meet minimum sampling duration or flow requirements. The mean relative standard deviation (RSD) (range) for indoor $\mathrm{PM}_{2.5}$ across the households with the repeated measurements was $37 \%$ (range: 0 - $86 \%$ [pre]) and 37\% (range: 7 - 79\%; [post]). The mean RSD (range) for indoor Abs across the same households was 31\% (range: 0 - 80\% [pre]) and 36\% (range: 2 - 65\%; [post]).

In addition, we used these repeated-measure samples to test the effect of sampling duration (24hour versus longer duration) on indoor air pollution concentrations. For the 13 households that completed two consecutive sampling days there were no statistically significant differences in $\mathrm{PM}_{2.5}$ and $\mathrm{Abs}$ levels between the two days in either the baseline $\left(\mathrm{PM}_{2.5} \mathrm{p}=0.32 ; \mathrm{Abs} \mathrm{p}=0.74\right)$ or post-intervention seasons $\left(\mathrm{PM}_{2.5} \mathrm{p}=1 ; \mathrm{Abs} \mathrm{p}=0.32\right)$. Similarly, in the 16 households with three consecutive day samples there were not statistically significant differences in air pollution levels between the sampled days in baseline $\left(\mathrm{PM}_{2.5} \mathrm{p}=0.61\right.$; $\left.\mathrm{Abs} \mathrm{p}=0.88\right)$ or post-intervention seasons $\left(\mathrm{PM}_{2.5} \mathrm{p}=0.72 ; \mathrm{Abs} \mathrm{p}=0.21\right)$. 
Figure S12: Comparison of Indoor 24-hour $\mathbf{P M}_{2.5}$ Sampling Vs. 72-hour Sampling

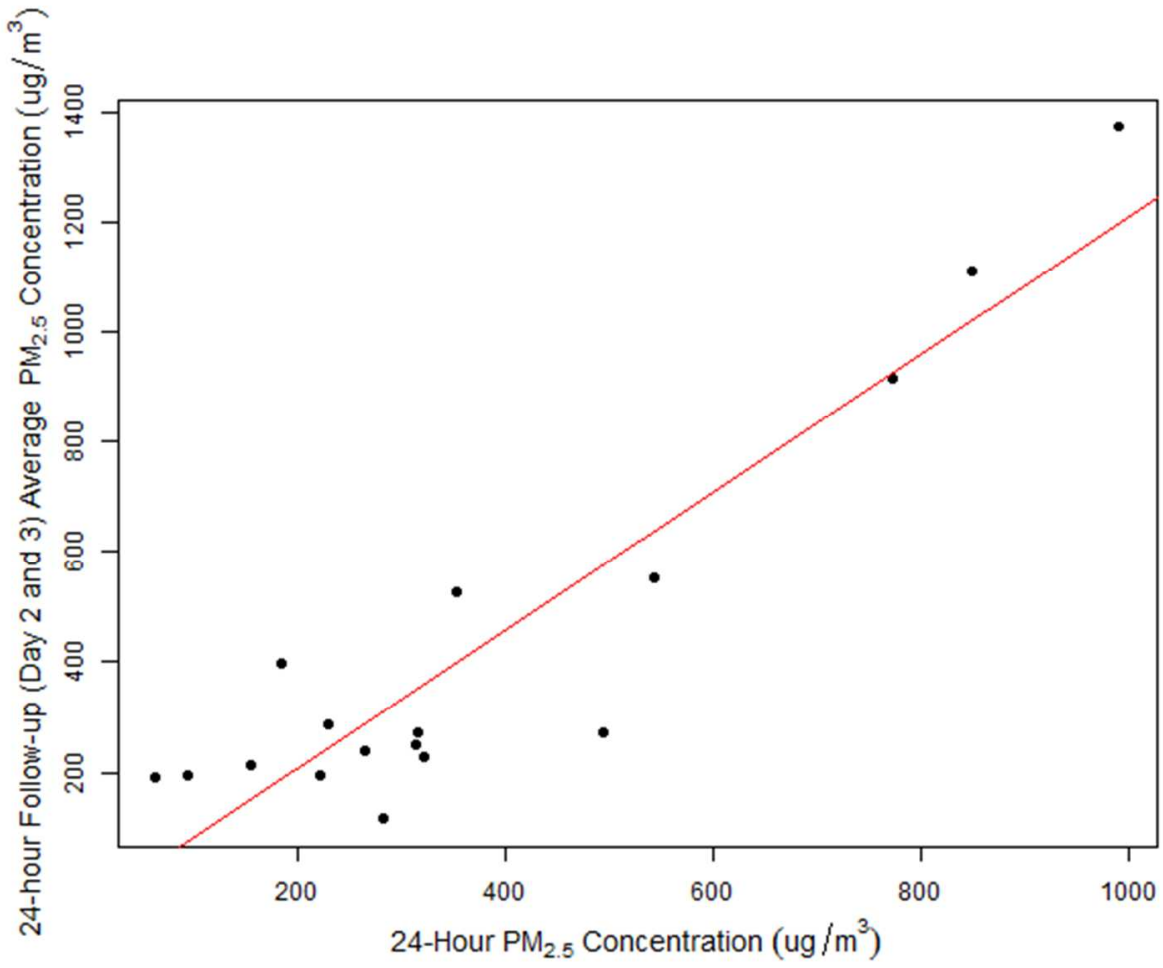

Figure S13: Comparison of Indoor 24-hour $\mathbf{P M}_{2.5}$ Sampling Vs. 48-hour Sampling

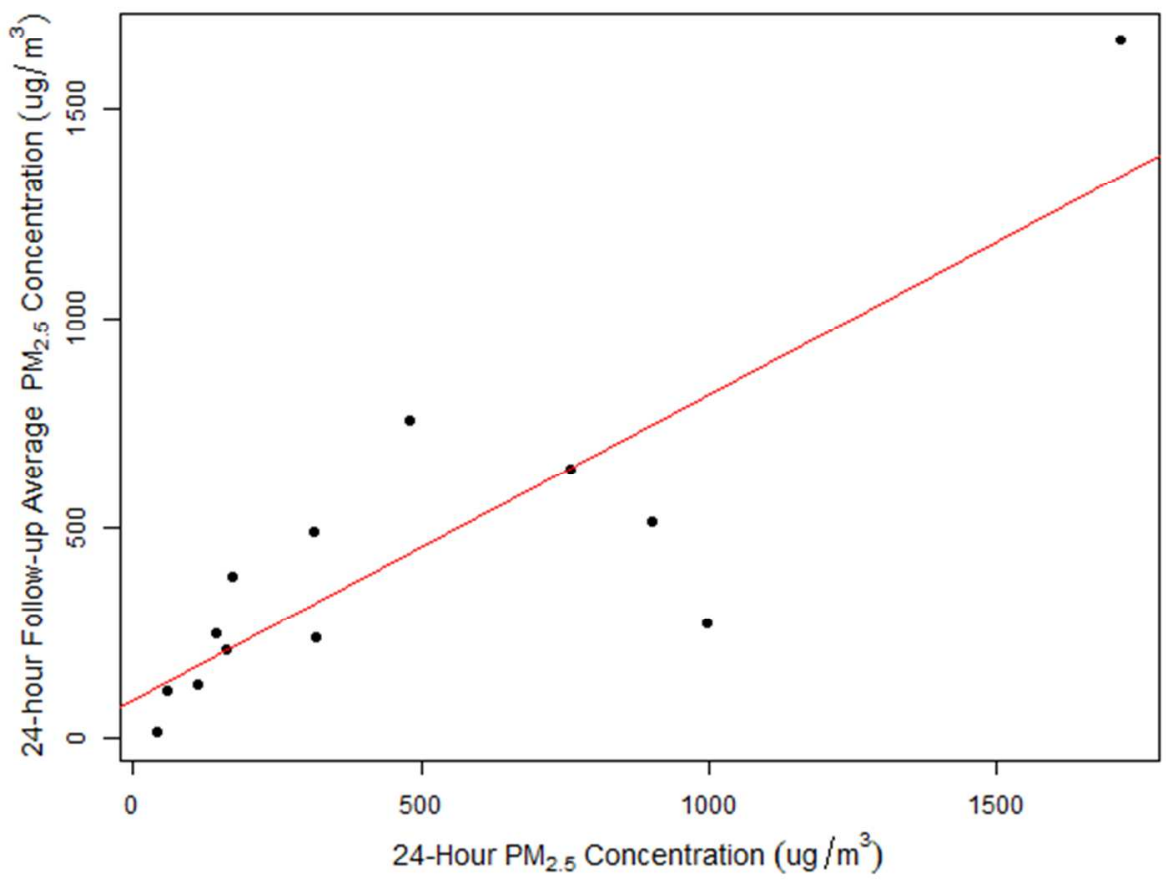


Figure S14: Change in Air Pollutant Concentrations by Randomized Groups
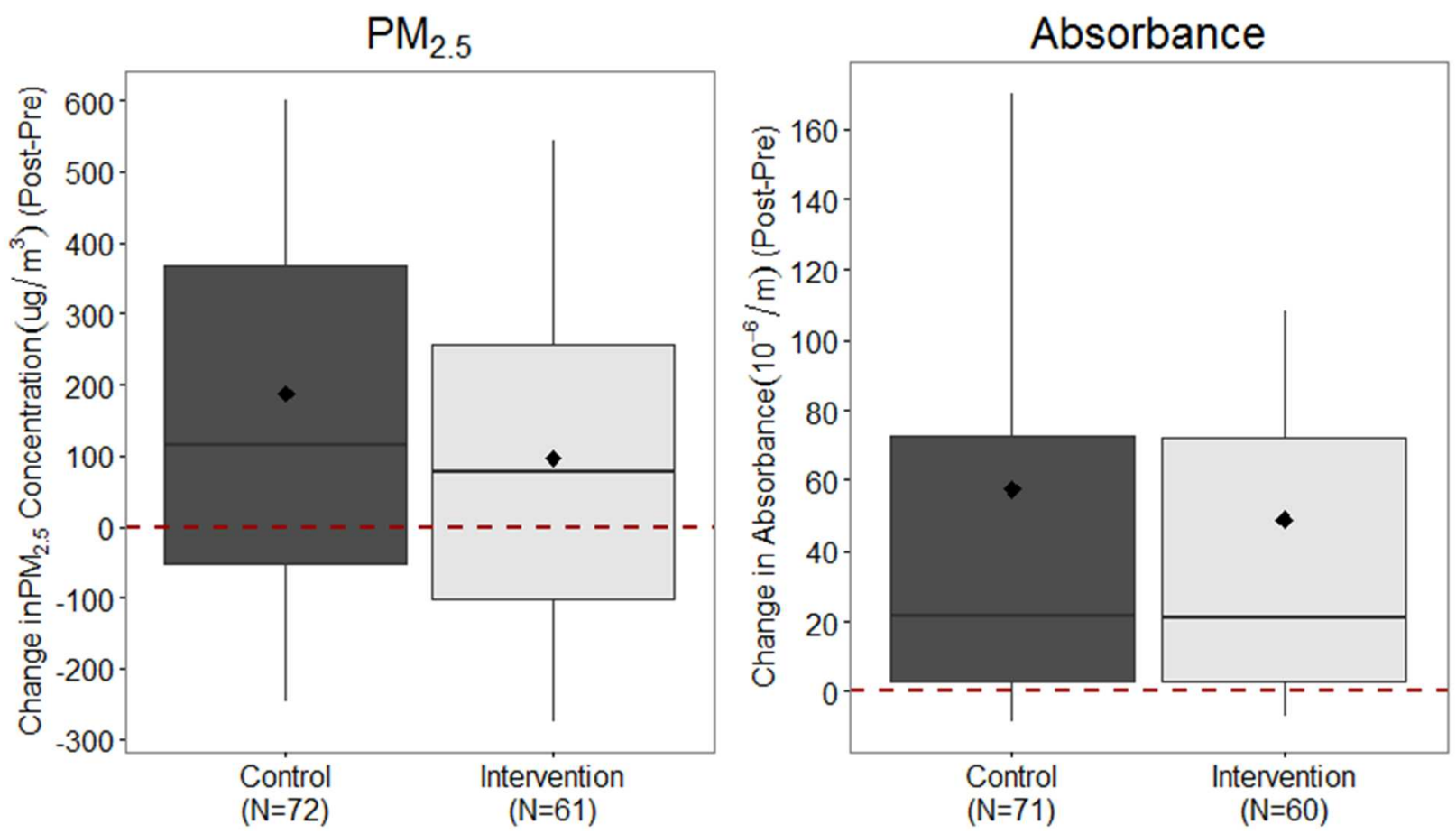

Note: lower and upper hinges represents the 25th and 75th percentiles, respectively; black line inside the box represents the 50th percentile; lower and upper whiskers represent the 10th and 90 th percentiles, respectively; and diamond represents the mean.

Figure S14 demonstrates seasonal change (post-intervention minus pre-intervention) in $\mathrm{PM}_{2.5}$ and Abs by control and intervention groups as randomized (ITT). A majority of homes in all groups experienced higher $\mathrm{PM}_{2.5}$ concentrations and $\mathrm{Abs}$ in the post-intervention season with median change for both pollutants above zero. The magnitude of the $\mathrm{PM}_{2.5}$ increase was smaller for the intervention group compared to the control. Median (SD) of seasonal difference for $\mathrm{PM}_{2.5}$ between control and exclusive stove groups are $114(602)$ and $75(407) \mu \mathrm{g} / \mathrm{m}^{3}$, respectively. This difference is borderline statistically significant for a one-tailed test $(p=0.14)$. The one-tailed test checks whether concentrations are statistically lower for the intervention than the control. For Abs, the seasonal change was similar between the control and intervention groups. 


\section{SI 8: Log-Linear Mixed-Effect Model}

We assigned household as the random effect because of repeated measures per household. We log-transformed $\mathrm{PM}_{2.5}$ and Abs concentrations to normalize skewed distributions. We controlled for the following covariates: ambient conditions (temperature, humidity, and outdoor $\mathrm{PM}_{2.5}$ or Abs concentrations), presence of chimney, and wood quantity and wood moisture.

Visual inspections of normal quantile plots of the random effect (household), and residuals of the mixed effect model suggest assumptions of normality were not violated.

$\mathbf{P M}_{2.5}$

$$
\begin{aligned}
& \log \left(\mathrm{PM}_{2.5}\right) \sim \beta_{1} \text { chimney }+\beta_{2} \text { wood use }+\beta_{3} \text { wood moisture }+\beta_{3} \text { outdoor } \mathrm{PM}_{2.5}+\beta_{4} \\
& \text { humidity }+\beta_{5} \text { outdoor temperature }+\beta_{6} \text { Stove use group } * \text { Season }+(1 \mid \text { household })+\varepsilon
\end{aligned}
$$

Table S8: Multivariate Adjusted Effects for Indoor $\mathbf{P M}_{2.5}$ Concentrations

\begin{tabular}{llllll} 
Fixed effects & Estimate $^{1}$ & Std. Error & df & t value & $\operatorname{Pr}(>|\mathbf{t}|)$ \\
\hline Intercept) & 5.325916 & 1.042894 & 189.8684 & 5.106862 & $7.93 \mathrm{E}-07 * * *$ \\
Chimney & -0.86441 & 0.148079 & 123.6953 & -5.8375 & $4.37 \mathrm{E}-08 * * *$ \\
24-hour Wood Use & 0.035865 & 0.030259 & 225.3189 & 1.185273 & 0.237158 \\
Wood Moisture & -0.01119 & 0.012543 & 192.6042 & -0.89202 & 0.373493 \\
Outdoor PM ${ }_{2.5}$ concentration & -0.0025 & 0.003594 & 215.1755 & -0.69415 & 0.488336 \\
Humidity & -0.00287 & 0.005781 & 185.21 & -0.4972 & 0.619635 \\
Temperature & 0.023168 & 0.029508 & 199.4677 & 0.78514 & 0.433303 \\
Exclusive Intv Stove Group & 0.090043 & 0.194512 & 203.5574 & 0.462914 & 0.64392 \\
Mixed Stove Group & 0.163337 & 0.231744 & 204.0722 & 0.704816 & 0.481728 \\
Post-intv Season & 0.434534 & 0.14538 & 136.0232 & 2.988949 & $0.003323 * *$ \\
Exclusive Intv Stove:Post-intv Season & -0.38729 & 0.212911 & 120.0261 & -1.81901 & 0.071404. \\
Mixed Stove: Post-intv Season & -0.09046 & 0.249593 & 119.2742 & -0.36241 & 0.717685 \\
\hline
\end{tabular}

Intv $=$ Intervention

Signif. codes: 0 '***’ 0.001 '**’ 0.01 '*’0.05'? 0.1 ' ' 1

${ }^{1}$ Unexponentiated estimates 


\section{Absorbance}

$$
\begin{aligned}
& \log (\text { Abs }) \sim \beta_{1} \text { chimney }+\beta_{2} \text { wood use }+\beta_{3} \text { wood moisture }+\beta_{3} \text { outdoor Abs }+\beta_{4} \text { humidity } \\
& +\beta_{5} \text { outdoor temperature }+\beta_{6} \text { Stove use group*Season }+(1 \mid \text { household })+\varepsilon
\end{aligned}
$$

\section{Table S9: Multivariate Adjusted Effects for Indoor Abs Concentrations}

\begin{tabular}{llllll} 
Fixed effects & Estimate $^{\mathbf{1}}$ & Std. Error & df & t value & $\operatorname{Pr}(>|\mathbf{t}|)$ \\
\hline Intercept) & 2.469897 & 0.961027 & 208.9278 & 2.57006 & $0.010864 *$ \\
Chimney & -0.47095 & 0.117127 & 115.5104 & -4.02084 & $0.000104 * * *$ \\
24-hour Wood Use & 0.023672 & 0.026747 & 224.2119 & 0.88503 & 0.377089 \\
Wood Moisture & -0.00115 & 0.01152 & 218.3425 & -0.0997 & 0.920672 \\
Outdoor PM ${ }_{2.5}$ concentration & 0.004065 & 0.003243 & 226.4036 & 1.253362 & 0.211367 \\
Humidity & 0.010857 & 0.005387 & 205.6134 & 2.015567 & $0.045147 *$ \\
Temperature & 0.003316 & 0.026813 & 217.2865 & 0.123681 & 0.901682 \\
Exclusive Intv Stove Group & -0.0544 & 0.16531 & 218.3977 & -0.32907 & 0.742414 \\
Mixed Stove Group & 0.090756 & 0.196958 & 217.7616 & 0.460789 & 0.64541 \\
Post-intv Season & 0.769263 & 0.140399 & 136.1285 & 5.479127 & $2.00 E-07 * * *$ \\
Exclusive Intv Stove:Post-intv Season & -0.03706 & 0.210306 & 117.4392 & -0.17623 & 0.860418 \\
Mixed Stove: Post-intv Season & 0.173519 & 0.247787 & 117.7501 & 0.700277 & 0.485136 \\
\hline
\end{tabular}

Intv $=$ Intervention

Signif. codes: 0 ‘***’ 0.001 '**’ 0.01 '*’ 0.05 '? 0.1 '’ 1

${ }^{1}$ Unexponentiated estimates

Table S10: Seasonal percent change in HAP concentrations by stove use groups (withingroup analysis)

\begin{tabular}{lccc} 
Stove Use Groups & Ratio & $\mathbf{9 5 \%} \mathbf{C I}$ & $\boldsymbol{p}$-Value \\
\hline $\mathbf{P M}_{\mathbf{2 . 5}}$ & & & \\
Control & 1.54 & $1.16,2.06$ & 0.003 \\
Exclusive Intervention Stove & 1.05 & $0.72,1.54$ & 0.81 \\
Mixed Stove & 1.41 & $0.87,2.28$ & 0.16 \\
& & & \\
Abs & & & $<.0001$ \\
\hline Control & 2.16 & $1.63,2.85$ & 0.0002 \\
Exclusive Intervention Stove & 2.08 & $1.43,3.02$ & 0.0001 \\
Mixed Stove & 2.57 & $1.61,4.10$ & \\
\hline
\end{tabular}


Table S11: Percent difference in HAP concentrations between stove use groups in postintervention season (between-group analysis)

\begin{tabular}{lccc} 
& Ratio & $\mathbf{9 5 \%}$ CI & P-Value \\
\hline $\mathbf{P M}_{\mathbf{2 . 5}}$ & & - & - \\
Control & Ref & $0.47,1.18$ & 0.29 \\
Exclusive intervention stove & 0.74 & $0.62,1.85$ & 0.95 \\
Mixed stove user & 1.08 & & \\
& & - & - \\
Abs & & $0.61,1.36$ & 0.85 \\
\hline Control & Ref & $0.81,2.09$ & 0.39 \\
Exclusive intervention stove & 0.91 & & \\
Mixed stove user & 1.30 & & \\
\hline
\end{tabular}

Chimney homes had 58\% and 38\% lower $\mathrm{PM}_{2.5}$ and $\mathrm{Abs}$, respectively, compared to non-chimney homes, and these effects were significant for both pollutants (Table S8; Table S9). Multivariate adjusted regression model showed the control group experienced a statistically significant $\mathrm{PM}_{2.5}$ increase of 54\% [95\% CI: $16 \%, 106 \%$ ] compared to pre-intervention season, whereas the $\mathrm{PM}_{2.5}$ increase in exclusive interventions stove $(5 \%[-28 \%, 54 \%])$ and mixed stove $(41 \%[-13 \%, 128 \%)$ groups were not statistically significant (Table S10). For Abs, all groups experienced statistically significant increases in post-intervention season compared to pre-intervention season. The Abs increases were 116\% [63\%, 185\%] for control; 108\% [43\%, 202\%] for exclusive intervention stove; and 157\% [61\%,310\%] for mixed stove groups (Table S10).

Differences between stove use groups in the post-intervention season are provided in Table S11. The exclusive intervention stove group had lower $\mathrm{PM}_{2.5}(-26 \%[-53 \%, 18 \%])$ and $\mathrm{Abs}(-9 \%[-$ $39 \%, 36 \%])$, respectively, compared to control group. Mixed stove homes had higher $\mathrm{PM}_{2.5}(8 \%$ $[-38 \%, 85 \%])$ and Abs $(30 \%[-19 \%, 109 \%])$ compared to control group. These effects were not statistically significant. 
Figure S15: Absorbance/PM2.5 Mass Ratio between Pre- and Post-Intervention Seasons (per-protocol analysis)

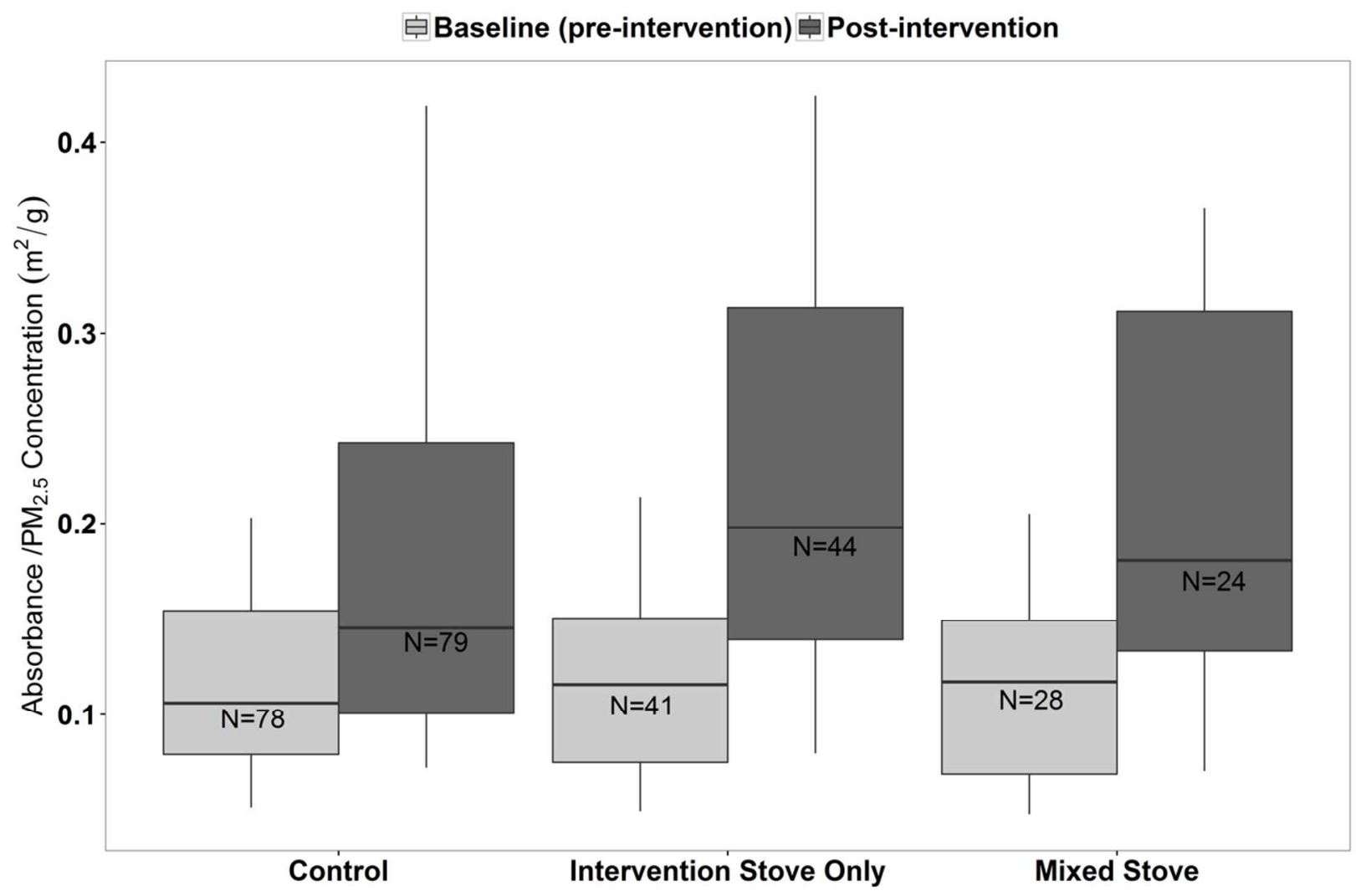

Note: lower and upper hinges represents the 25th and 75th percentiles, respectively; black line inside the box represents the 50th percentile; lower and upper whiskers represent the 10th and 90th percentiles, respectively.

Figure S15 is Absorbance: $\mathrm{PM}_{2.5}$ ratios between pre- and post-intervention seasons by stove use groups. The Absorbance: $\mathrm{PM}_{2.5}$ ratios were higher in the post-intervention season (darker boxes) in all stove use groups. The two intervention groups (intervention stove only and mixed stove groups) experienced higher Abs: $\mathrm{PM}_{2.5}$ ratios compared to control group. 
Figure S16: Change in $\mathbf{P M}_{2.5}$ by Stove Use and Chimney

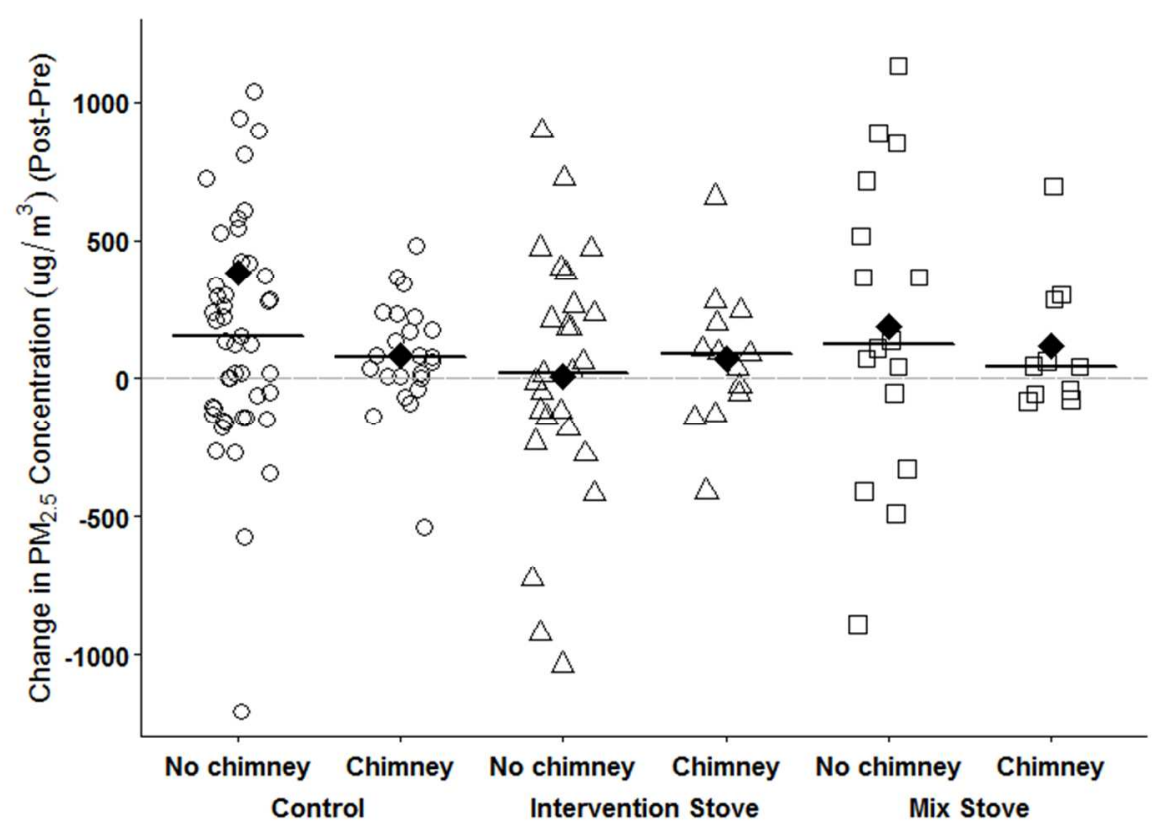

Figure S17: Change in Absorbance by Stove Use and Chimney

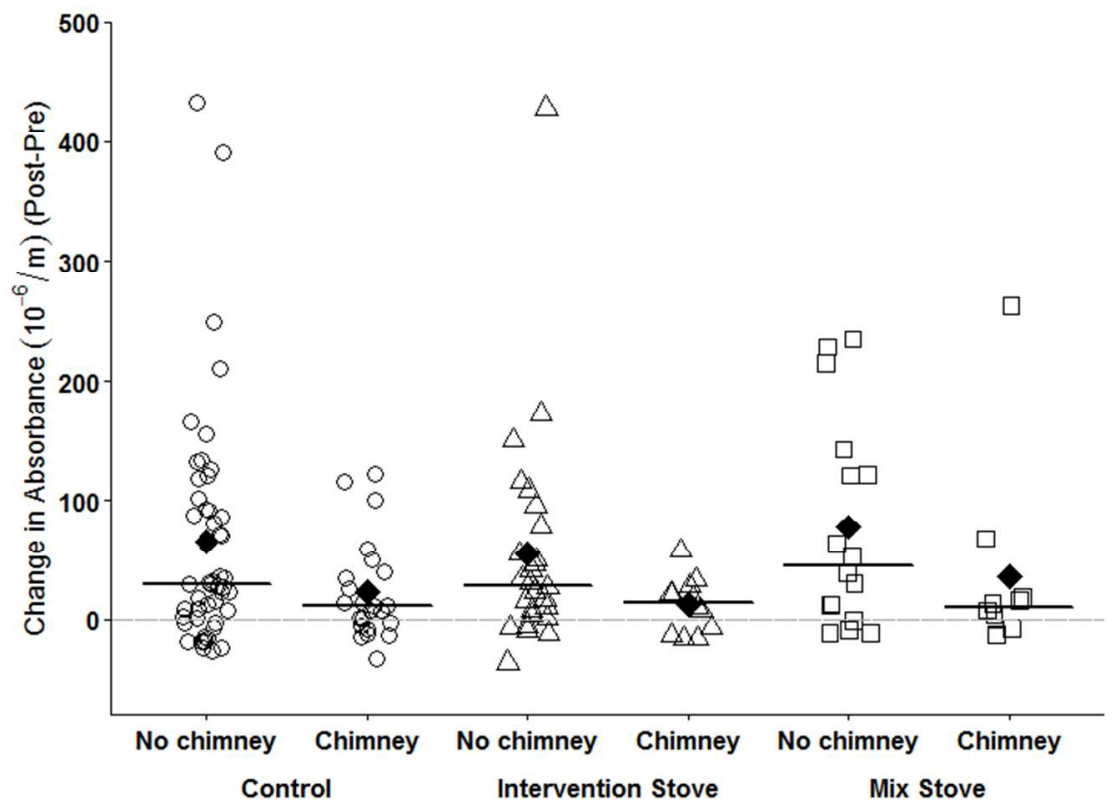

Median and mean are represented by black horizontal line and diamond symbols, respectively. Due to outliers, $y$-axis for PM 2.5 graph zoomed in to show median and mean around zero; data from 3 households (2\% of data) not shown as a result since change in $P_{2.5}$ concentration was above $2,000 \mu \mathrm{g} / \mathrm{m}^{3}$. 


\section{DISCUSSION SECTION}

\section{SI 8: Time-weighted total exposure}

A rough estimation of time-weighted total exposure from time use data is $225 \mu \mathrm{g} / \mathrm{m}^{3}$. We derived this number from an estimated amount of time a typical woman in the study village spends outdoor ( $\sim 10$ hours) either working in a farm or outside her house, with an average outdoor village PM concentration of $23 \mu \mathrm{g} / \mathrm{m}^{3}$. The rest of the 14 hours is spent indoor (cooking, cleaning, childcare, etc.) where mean indoor concentration is $370 \mu \mathrm{g} / \mathrm{m}^{3}$.

Weighed total exposure:

a. $\left[\left(10 \mathrm{hrs} * 23 \mu \mathrm{g} / \mathrm{m}^{3}\right)+\left(14 \mathrm{hrs} * 370 \mu \mathrm{g} / \mathrm{m}^{3}\right)\right] / 24$ hours $=225 \mu \mathrm{g} / \mathrm{m}^{3}$

Indoor exposure accounted for $96 \%$ of the total time-weighted average exposure in the study population

\section{Cited literature for Supporting Information}

(1) United Nations Framework Convention on Climate Change. AMS-II.G.: Energy efficiency measures in thermal applications of non-renewable biomass --- Version 7.0, Valid from $24 \mathrm{Jul} 15$ onwards http://cdm.unfccc.int/methodologies/DB/KZ6FQOCEEHD1V02ARWTW1W2R9G45BX (accessed Mar 3, 2016).

(2) CDM Executive Board. Project Design Document Form (CDM-SSC-PDD) - Version 03; UNFCCC, 2006.

(3) Rehman, I. H.; Ahmed, T.; Praveen, P. S.; Kar, A.; Ramanathan, V. Black carbon emissions from biomass and fossil fuels in rural India. Atmos. Chem. Phys. 2011, 11, 7289-7299. 